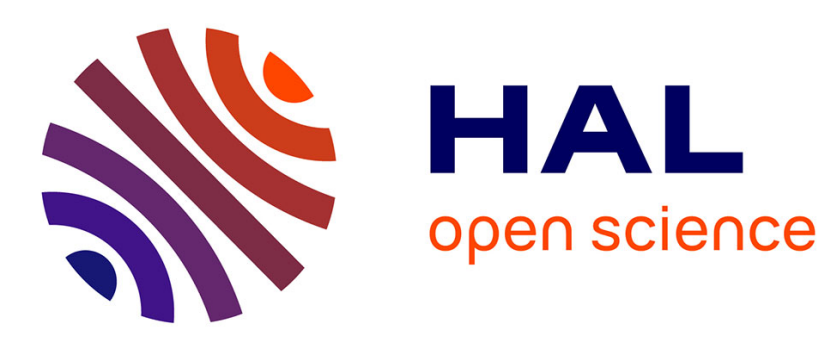

\title{
Active Role-Based Database System for Factory Planning
}

\author{
Uwe Dombrowski, Christoph Imdahl, Alexander Karl
}

\section{To cite this version:}

Uwe Dombrowski, Christoph Imdahl, Alexander Karl. Active Role-Based Database System for Factory Planning. IFIP International Conference on Advances in Production Management Systems (APMS), Aug 2018, Seoul, South Korea. pp.422-430, 10.1007/978-3-319-99707-0_53 . hal-02177843

\section{HAL Id: hal-02177843 \\ https://hal.inria.fr/hal-02177843}

Submitted on 9 Jul 2019

HAL is a multi-disciplinary open access archive for the deposit and dissemination of scientific research documents, whether they are published or not. The documents may come from teaching and research institutions in France or abroad, or from public or private research centers.
L'archive ouverte pluridisciplinaire HAL, est destinée au dépôt et à la diffusion de documents scientifiques de niveau recherche, publiés ou non, émanant des établissements d'enseignement et de recherche français ou étrangers, des laboratoires publics ou privés.

\section{(c)(1)}

Distributed under a Creative Commons Attribution| 4.0 International License 


\title{
Active role-based database system for factory planning
}

\author{
Uwe Dombrowski ${ }^{1}$, Christoph Imdahl $^{1 *}$, Alexander Karl ${ }^{1}$ \\ ${ }^{1}$ Institute for Advanced Industrial Management (IFU) \\ Technische Universität Braunschweig, Langer Kamp 19, 38106 Braunschweig, Germany \\ *Corresponding author. Tel: +49 531391 2703, E-mail: c.imdahl@tu-bs.de
}

\begin{abstract}
The globalization of markets and the paradigm shift to mass customization lead to a turbulent planning environment. For companies, this results in an increased planning frequency and an increased volume of planning data in the factory planning process. Solutions are the concepts of the Digital Factory and the Digital Shadow. In the context of these two concepts, database systems must be integrated into systematic planning tools in order to make continuous and active use of factory planning knowledge and to reduce the amount of data to the required. Against this background, the paper proposes a concept for the development of an active role-based database system that converts information from various sources into manageable restrictions and filters them by assigning them to the relevant planning phase and to the responsible employee in the company. To validate the concept, the database system is integrated in a factory planning table. A use case shows, that in combination with the planning table, the database system reduces the planning time of factories and at the same time improves planning quality by integrating stored planning knowledge.
\end{abstract}

Keywords: Digital Factory, Database System, Factory Planning.

\section{Global factors influencing factory planning processes in companies}

Due to the globalization of markets and the paradigm shift in production from mass production to customized mass production, product cycles and the degree of individualization as well as the complexity of products have been decreasing for years [1,2]. As a result, companies' planning processes have to meet customer demands for more variants, in the shortest possible delivery times and maximum transparency across the entire business processes [3,4]. Under these circumstances, there is an increase in planning frequency, the volume of planning data raises and requires its exchange through further interfaces along the value chain. Therefore, new methods and instruments have become necessary in order to master the increasingly complex product and production development processes economically [1]. One solution is the systematic use of planning methods and virtual planning and validation in order to implement the modifications in the existing or new factory after successful evaluation $[3,4,5]$. 


\section{Digital Factory and Digital Shadow}

The mentioned solution approach is summarized under the concept of the Digital Factory. According to the widely accepted VDI 4499 definition, the Digital Factory is an approach that includes digital models, methods and tools that support early parallelization and digital processing from product development and production planning to virtual start-up and operation [1]. Therefore, the Digital Factory is a digital model of the physical structure of a factory but does consider non-physical aspects such as existing knowledge as well [4,6]. The goal is an integrated planning, evaluation and continuous improvement of the essential structures and processes of the real factory in relation to the product [1]. Accordingly, data integration and digital plausibility checks, can increase the planning speed by approx. $20 \%$ and the planning quality by 10 to $15 \%[7,8]$. Due to further developments in data processing in the digital age, the concept of Digital Shadows has gained in importance beside the Digital Factory [9]. The Digital Shadow is a digital image of the real-time data in production, development and other areas with sufficiently detailed accuracy [10]. Therefore, the Digital Factory is the static digital image of the factory and is created from historical data of the real factory, while the Digital Shadow is a real-time model of the factory. The simulations of both approaches help to achieve improvements in the current factory, so both concepts are closely linked [9]. In the future, factory planning with the Digital Factory and the Digital Shadow will require the intelligent use of existing digital data to extract planning knowledge and integrate it into the planning process [11]. For this purpose, database tools must be created to systematically convert planning data into stored planning knowledge and to use it actively across all planning phases of the factory planning process $[3,5,12]$. In addition, the tools must have a human-oriented visualization in order to include all persons who must be jointly involved in solving specific tasks $[5,13]$.

\section{$3 \quad$ Meaning of database systems for factory planning}

A database system consists of a database and a data management system. These two components enable the structuring, storage and provision of data and thus the automation of planning steps [14]. The planning of a factory is divided into creative processes and routine tasks. For the creative processes, the participative factory planning approach is mostly used, in which all planners work together on the same planning status to create many creative variants with high planning quality [4]. Therefore, the objective of database systems is to automate routine tasks such as calculations or the consideration of requirements in order to create more freedom for creative tasks [15].

Database systems support the factory planning process with the following functions:

- Collection of planning know-how from experienced employees and continuous improvement of the database through further project experience

- Knowledge accumulation is supported by structured and retrievable data

- Offering predefined modules, such as social rooms or standard workstations in libraries 
With these functions, database systems enable even inexperienced planners to quickly plan different variants of production layouts with high quality and compare these planning alternatives [15].

However, the use cases show that current database systems only provide planning knowledge passively, which means that the planner must actively extract the information from the database himself. The database system described below differentiates itself at this point by making the planning knowledge actively available, since it continuously checks the planning status according to validity in real time. The appropriate planning knowledge is then assigned and provided to the responsible employee. In participative, creative planning processes, planners therefore know immediately whether the planning status is valid and which changes must be made.

\section{Design of an active role-based database system for factory planning}

In accordance with the requirements elaborated in the previous chapter, this paper proposes a design for a database system for factory planning. In summary, the aim of the database system is to intuitively support the planner in the respective factory planning phase by actively providing planning knowledge to the relevant employee during the planning process. To achieve this goal, the functional principle of the database system shown in figure 1 consists of four modules. These pursue four subgoals in order to enable active provision of planning knowledge.

1. Building a Database by capturing data and knowledge for factory planning from different sources in different fields for the factory planning procedure.

2. Validating the planning status by structuring the data into requirements, transferring it into logical arguments and linking it to planning objects

3. Actively providing and filtering unfulfilled requirements by factory planning and role in the company.

4. Enable the traceability of requirements to their original document in order to prove that special requirements have been planned.

The four modules are explained in detail in the following subchapters. 


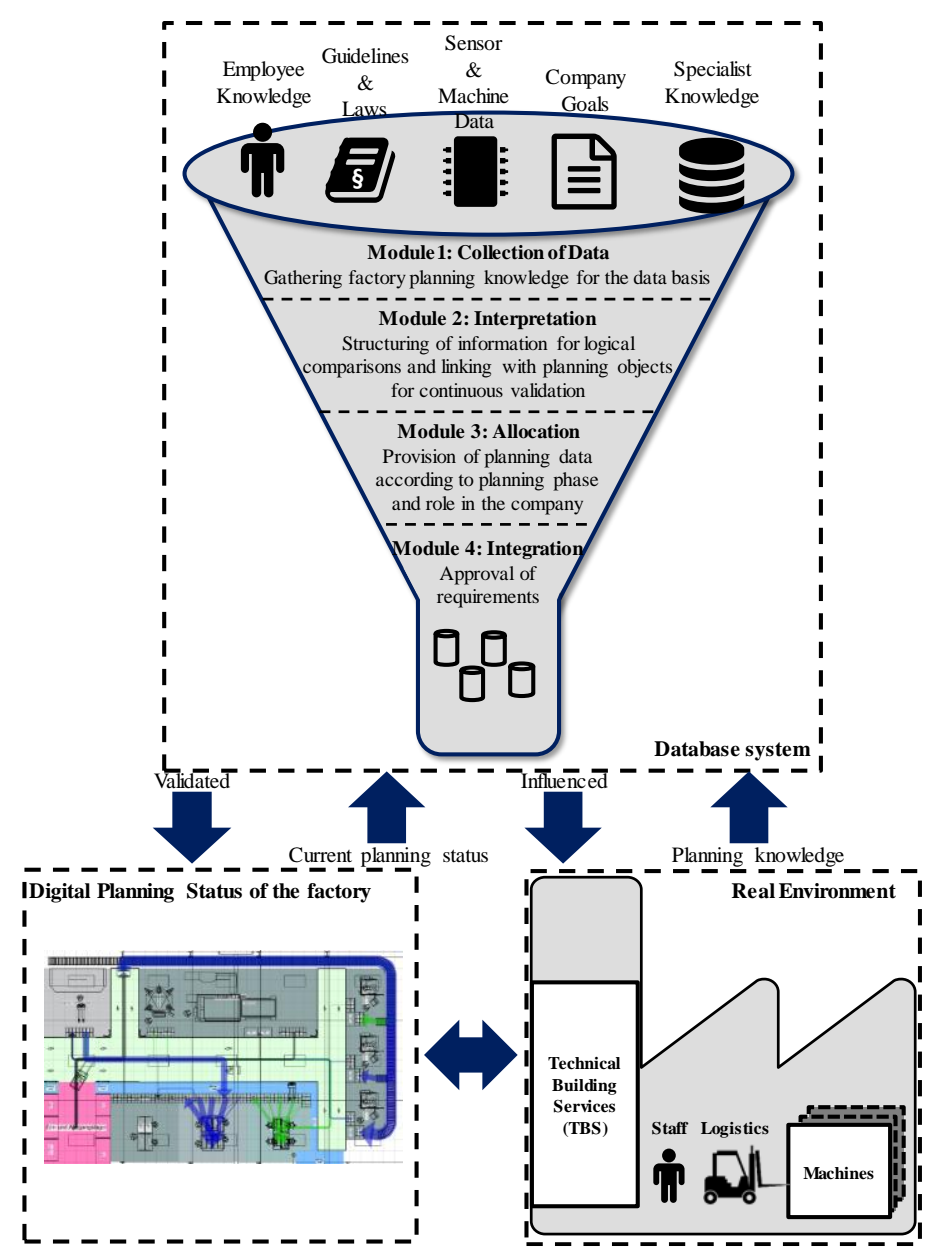

Fig. 1. Concept for the database system for factory planning

\subsection{Module 1: Capturing Data}

In Module 1 information relevant to the factory planning process must be collected from different sources in different fields. This step generates the factory planning-specific database, which is structured and filtered in the following modules. The database requires the following data:

Type of information: The type assigns they can be assigned to the subject areas. Examples in the factory planning process are e.g. environmental, work safety, etc.

Source: Indicates the document in which the original claim was formulated and is readable.

Specific page: Specifies the exact location of the information in the original document in order to avoid longer search effort for sources with several pages.

Publisher: Can be persons, organizations or entities who have written the information. 
Revision level: Displays the current status of the information and allows the system to add and update information.

Serial number: Enables the unique determination of the information if several requirements can be recorded from one source. The unique identification of data is an important premise for the database.

Original text of the requirement: Literally describes the content of the information and is therefore unaltered, since the information is available without interpretation.

With the specified data, requirements can be recorded, clearly determined and traced back to the exact place of origin within the original document.

\subsection{Module 2: Interpretation and linking of information}

In module 2, the most significant step of the database system is performed by converting the information into if-then conditions and linking them to specific planning objects, such as production machines. In this structure, the database system can use the data from the real factory and the digital planning status to check whether the production requirements have been taken into account. The following steps are performed for this structuring process. In the first step, production requirements are determined from the information stored in the database. These requirements are formulated with as few words as possible in order to avoid ambiguities. Once the requirement has been formulated, it must be converted into a logical if-then comparison. Finally, this condition is linked to an object or element in the factory so that the system can check the requirement. The link also shows the planner what needs to be changed so that the planning status becomes valid.

\subsection{Module 3: Allocating requirements in the factory planning process}

In order to process the large number of restrictions formed in the factory planning process, it is necessary that the requirements for the factory and production planning are filtered and made available in a targeted manner. First, the planning knowledge is filtered according to the factory planning phase so that only relevant information is considered in the respective planning process. To ensure that the unfulfilled requirements are processed in a goal-oriented manner, they are then actively assigned to the responsible role in the company. The roles in the company are in turn linked to one or more employees, who is responsible for the unfulfilled requirement.

\subsection{Module 4: Integration of requirements}

The last module is a release process that checks new factory or production requirements and changes before they are taken into account in the planning process. The purpose of the approval process is to prevent incorrect or obstructive requirements from slowing down the planning process or reducing the quality of planning. The release is carried out by the factory planner as he has the know-how to check the relevance of the data, tasks and restrictions and to decide whether the classification in the planning phase is correct. 


\section{$5 \quad$ Use Case: Participative factory planning with the IFU factory planning table 4.0 and the database system}

As already explained in Chapter 3, the concepts of the Digital Factory and the Digital Shadow require new forms for planning workplaces. One widely used approach is participative factory planning [4]. Planning tables have established themselves as helpful assistance systems for this creative form of factory planning, because they allow a group of planners to plan simultaneously at the same planning stage.

The IFU factory planning table 4.0 was developed at the Institute for Advanced Industrial Management (IFU) of the Technische Universität Braunschweig. Figure 2 shows the functional principle of the planning table with the application cycle of the database system. The aim of the IFU factory planning table 4.0., in the context of participatory factory planning, is to include all knowledge carriers in the planning process in order to implement a valid layout within the shortest planning time with the best planning quality. For this purpose, the table has a 65-inch touch display on which parallel cooperation is possible. On this multi-touch interface, users can insert objects using Marker with 3D representations and design the layout by moving the markers and using gestures on the touch surface. The application cycle shows that every time the planners modify the planning status, by adding new objects or changing the layout, the database system checks whether all requirements for the factory that are linked to objects have been met. If all requirements have been met, the planning status is evaluated as valid. For all unfulfilled requirements, a message is generated from the short description and shown to the responsible employee in the summary on the display. With cameras under the planning table, employees can be identified by their badges, so that the logged in employee only receives notifications concerning his role in the company. If the planner needs more detailed information in addition to the general description, the planning table provides the linked source for the requirement. This application cycle enables planners to work through the planning processes for a new factory step-by-step on one planning status and generate a valid, evaluated layout within less time.

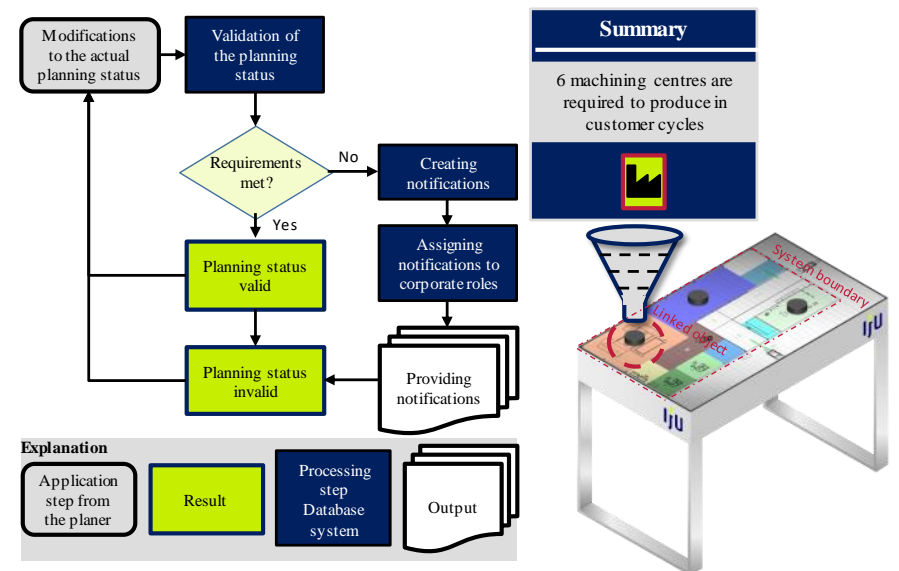

Fig. 2. : Application cycle of the database system on the IFU factory planning table 4.0 
In a factory planning project with a medium-sized company, the combination of IFU factory planning table 4.0 and database system was used. The aim of the project was to check the initial layout derived from an existing production plant for optimality and validity so that the construction project could begin. With the initial layout, new variants were created in a workshop with the planning group consisting of eight people at the planning table. In addition to several smaller requirements, the developed database system was able to avoid serious planning errors and adding value by:

- Consideration of an additional machining center, due to the reduction of the customer cycle through the new production program

- Correct dimensioning of the driveways for loading and unloading of goods from the newly planned continuous flow rack

- Shift participants' focus to finding creative solutions to requirements rather than thinking about unnoticed problems

To illustrate how it works, table 1 shows an excerpt from the database system for the listed requirements.

The generated variants from the workshop were then summarized into a valid planning status that combines most of the benefits. In this way, a very good and valid planning status for the start of the construction project could be planned in a two-week project. The use case shows the relevance of the active provision of information by the developed database system in the participative factory planning process in order to create space for the creative planning processes and to achieve a high planning quality.

Table 1. Extract of the database system with described requirements

\begin{tabular}{|c|c|c|c|c|c|c|c|c|c|c|}
\hline \multicolumn{4}{|c|}{ Collection of Data } & \multicolumn{4}{|c|}{ Interpreation and Linkin } & \multicolumn{2}{|c|}{ Allocating } & \multirow{2}{*}{$\begin{array}{l}\text { Integratior } \\
\text { Approved }\end{array}$} \\
\hline $\begin{array}{c}\text { Type of } \\
\text { Information }\end{array}$ & Soruce & $\begin{array}{c}\text { Serial } \\
\text { Number }\end{array}$ & Original text & Short description & Logical Equation & $\begin{array}{l}\text { Linked } \\
\text { Object }\end{array}$ & Value & \begin{tabular}{|c} 
Factory \\
planning step
\end{tabular} & Role & \\
\hline $\begin{array}{c}\text { Material } \\
\text { flow }\end{array}$ & $\begin{array}{c}\text { Production } \\
\text { Program }\end{array}$ & $1 \_1$ & \begin{tabular}{|} 
The analysis indicates that 6 \\
machining centres and 4 assembly \\
stations are required for \\
production in customer cycles.
\end{tabular} & $\begin{array}{l}6 \text { machining centres are } \\
\text { required for production }\end{array}$ & $\begin{array}{c}\text { If number of linked } \\
\text { objects }<6 \text {, then False }\end{array}$ & $\begin{array}{c}\text { Maching } \\
\text { Center }\end{array}$ & FALSE & $\begin{array}{r}\text { Layout } \\
\text { planning }\end{array}$ & $\begin{array}{c}\text { Production } \\
\text { planner, CEO }\end{array}$ & Yes \\
\hline Logistics & $\begin{array}{l}\text { Technical } \\
\text { Document }\end{array}$ & $2 \_1$ & $\begin{array}{l}\text { The track for loading and } \\
\text { unloading must be } 2.5 \mathrm{~m} \text { wide. }\end{array}$ & \begin{tabular}{|c|} 
The track for loading \\
and unloading must be \\
$2.5 \mathrm{~m}$ wide.
\end{tabular} & \begin{tabular}{|c|} 
If distance of an object \\
to the linked object < \\
$2,5 \mathrm{~m}$, then False
\end{tabular} & Flow Rack & FALSE & $\begin{array}{c}\text { Layout } \\
\text { planning }\end{array}$ & $\begin{array}{c}\text { Production } \\
\text { planner, CEO }\end{array}$ & Yes \\
\hline $\begin{array}{r}\text { Work } \\
\text { Safety } \\
\end{array}$ & Directive & $3 \_1$ & The escape route must be free & $\begin{array}{c}\begin{array}{c}\text { The escape route must } \\
\text { be free }\end{array} \\
\end{array}$ & \begin{tabular}{|l|}
$\begin{array}{l}\text { If the distance of an } \\
\text { object to the linked } \\
\text { object }=0 \text {, then False }\end{array}$ \\
of
\end{tabular} & Escape Route & FALSE & $\begin{array}{r}\text { Layout } \\
\text { planning }\end{array}$ & \begin{tabular}{|c} 
Safety Officer, \\
Logistics \\
specialist \\
\end{tabular} & Yes \\
\hline
\end{tabular}

\section{Summary and outlook}

With the concepts of the Digital Factory and the Digital Shadow, the use of digital planning tools has become an essential success factor in the factory and production planning of manufacturing companies. Especially the reduction of the provided data to the most essential data for the specific process will gain more and more importance. The presented database system enables the storing of planning knowledge and continuous monitoring of the planning status. It differs from existing database systems primarily in the active provision of planning knowledge which is filtered according to factory planning phase and role, so that an active and sustainable use of stored knowledge is possible. The use case shows that implementing the database system in a 
factory planning tool, such as the planning table, leads to a faster and more creative planning process with higher planning quality. This allows the planning process to focus on the disclosure of implicit expert knowledge of the employees. The disadvantage of such a system is the increased initialization effort, therefore future research is mainly needed to automate the initialization and updating of the database with the requirements through the direct coupling of the database with the real production via digital shadow.

\section{References}

1. VDI 4499: VDI 4499 Part1: Digital Factory - Fundamentals (2008).

2. Hu, S. J., Ko, J., Weyand, L., Elmaraghy, H. A., Lien, T. K., Koren, Y., Chryssolouris, G., Nasr, N., Shpitalni, M.: Assembly system design and operations for product variety. CIRP Annals - Manufacturing Technology, Vol. 60, No. 2, 715-733 (2011).

3. Bley, H., Fritz, J., Zenner, C.: Die zwei Seiten der Digitalen Fabrik. ZWF Vol. 101, No. 12, 19-23 (2006).

4. Dombrowski, U., Bothe, T., Tiedemann, H.: Visionen für die Digitale Fabrik. ZWF, Vol 96, No. 3, 96-100 (2001).

5. Westkämper, E., Bischoff, J., Briel, R., von Dürr, M. Factory Digitalizing: An adapted approach to a digital factory planning in existing factories and buildings. Werkstattechnik online, Vol. 91, 304-307 (2001).

6. Gregor, M., Medvecky, S.: Digital Factory - Theory and Practice. Engineering the Future: Sciyo (2010)

7. Kühn, W.: Digital Factory- Integration of Simulation Enhancing the Product and Production Process towards Operative Control and Optimisation. Electrical, Information and Media Engineering, University of Wuppertal, Wuppertal (2006).

8. Haller, E., Schiller, E., Emmerich, F., Hartel, I.: Impact of the Digital Factory on the Production Planning Process. International Conference for Information Processing, Bd. 160, 7384 (2005).

9. Wohlfeld, D., Weiss, V., Becker, B.: Digital Shadow - From production to product. 17. Internationales Stuttgarter Symposium, Springer Fachmedien Wiesbaden, 783-794 (2017).

10. Bauernhansl, T., Krüger, J., Reinhart, G., Schuh, G.: WGP-Standpunkt Industrie 4.0. WGP, Darmstadt (2016).

11. Deuse, J., Eigner, M., Erohin, O., Krebs, M., Schallow, J., Schäfer, P.: Intelligente Nutzung von implizitem Planungswissen der Digitalen Fabrik. ZWF Vol. 106, No. 6, 433-437 (2011).

12. Zäh, M. F., Patron, C., Fusch, T.: Die Digitale Fabrik. ZWF, Vol 98, No. 3, 75-77 (2003)

13. Eigner, M.; von Hauff, M.; Schäfer, P. D.: Sustainable Product Lifecycle Management: A Lifecycle based Conception of Monitoring a Sustainable Product Development. 18th CIRP International Conference on Life Cycle Engineering, in: Hesselbach, J.; Herrmann, C.: Glocalized Solutions for Sustainability in Manufacturing. Springer-Verlag, Berlin, 501-506 (2011).

14. Kemper, A., Eickler, A.: Datenbanksysteme: Eine Einführung. De Gruyter, 10th Edition, München (2015)

15. Bracht, U., Geckler, D., Wenzel, S.: Digitale Fabrik. Springer Vieweg, 2nd Edition, Heidelberg (2018). 